Bangladesh Journal of Anatomy January 2009, Vol. 7 No. 1 pp. 49-54

\title{
Morphological Changes of Placenta in Preeclampsia
}

\author{
Segupta Kishwara ${ }^{1}$, Shamim Ara $^{2}$, Khandaker Abu Rayhan ${ }^{3}$, Mahamuda Begum $^{4}$
}

\begin{abstract}
:
Context: Preeclampsia is regarded as a risk factor in pregnancy and it leads to placental insufficiency. This, in turn causes both maternal and fetal morbidity and mortality. The present study intends to compare the morphological changes of placenta in preeclampsia with that of normal placenta.
\end{abstract}

Study design: A descriptive type of study.

Place and period of study: Department of Anatomy, Dhaka Medical College, Dhaka, from August 2005 to June 2006.

Materials: 60 human placentae, 30 were from normal pregnant women as control and 30 from pregnancies complicated by preeclampsia were taken for this study.

Method: Samples were grouped as Group A and Group B on the basis of presence or absence of preeclampsia. All samples were studied morphologically.

Result: Different shapes of placenta were found with some having accessory lobes in both groups. There was significant reduction $(p<0.001)$ in diameter and volume of placenta in Group $B$. The thickness of placenta was reduced in Group $B$ but the difference did not reach a significant level. The number of cotyledon was significantly reduced in Group B $(p<0.05)$.

Conclusion: In this study, it was found that the preeclamptic placentae underwent definite morphological changes. These changes seemed to be the result of insufficiency of placenta in preeclampsia. However, further histological and morphometric placental study in a larger sample has to be conducted to come up with a conclusive decision.

Key Words: Placenta, Preeclampsia, Morphology.

\section{Introduction:}

Despite the significant achievements made by Bangladesh in health, maternal mortality continues to be significantly high. Each year twelve thousand mothers die in Bangladesh during childbirth while maternal mortality is 320 per 100,000 live births ${ }^{1}$.

Placenta is a leading cause of maternal and perinatal mortality $^{2}$ and an important factor in fetal growth retardation as it is commonly associated with placental insufficiency ${ }^{3}$.

1. Assistant Professor (c.c.), Department of Anatomy, Dhaka Medical College, Dhaka

2. Professor and Head, Department of Anatomy, Dhaka Medical College, Dhaka

3. Assistant Professor, Department of Anatomy, Southern Medical College, Chittagong

4. Associate Professor, Department of Anatomy, Dhaka Community Medical College, Dhaka

Correspondence: Dr. Segupta Kishwara
In normal pregnancies, the wall of the spiral arteries is invaded by trophoblastic cells and transformed into large, tortuous channels that carry a large amount of blood to the intervillous space and are resistant to the effects of vasomotor agents. Trophoblastic invasion begins from 16-20 weeks of gestation causing destruction of the muscularis layer of spiral arteries land is completed by 24 weeks' time. These physiologic changes are restricted in patients with preeclampsia ${ }^{4}$. The main feature of abnormal placentation is inadequate trophoblastic invasion of the maternal spiral arteries. This results in persistence of muscular and elastic tissues of the media of spiral arteries. As a result, the vessels fail to dilate and remain responsive to vasomotor influences that lead to high resistance low flow chorio-decidual circulation. With progress of pregnancy, the metabolic demand for the fetoplacental unit increases but the spiral arteries are 
unable to dilate to accommodate the required increase in blood flow, resulting in placental dysfunction that manifest clinically as preeclampsia ${ }^{5}$. Although the pathophysiology of preeclampsia is poorly understood, it is characterized by abnormal trophoblst invasion of uterine blood vessels, immunological intolerance between feto-placental and maternal tissues ${ }^{6}$.

Babies born with a disproportional large placenta are at a greater risk of developing hypertension in later life ${ }^{7}$. Careful examination of placenta can give information that may be important in the immediate and later management of mother and infant.

The objective of the present study is to compare the morphological changes of placenta in preeclampsia with that of normal placenta.

\section{Materials and Methods:}

The study was carried out on 60 placentae, 30 were from normal pregnant women considered as control, and 30 from pregnancies complicated by preeclampsia in previously normotensive women. The placentae were collected from Obstetrics and Gynecology department of Dhaka Medical College Hospital and Sir Sallimullah Medical College Hospital.

Grouping of the Sample:

Samples were divided into two groups as Group A and Group B according to presence or absence of preeclampsia.

Group A (Control Group): This group comprises pregnant women without preeclampsia, women had normal blood pressure, no proteinuria and no edema.

Group B (Preeclampsia Group): This group comprises pregnant women with preeclampsia i.e. women of this group had blood pressure at or above $140 / 90 \mathrm{~mm} \mathrm{Hg}$ on at least two occasions, six or more hours apart after 20 weeks of present pregnancy together with albuminuria and edema.

\section{Variable Studied:}
1. Shape
2. Diameter
3. Thickness
4. Volume
5. Number of cotyledons

\section{Procedure of the Study:}

1. Shape of placenta:

The shape of the placenta and presence of accessory lobe were recorded after proper inspection. Each placenta was categorized as oval, circular or irregular in shape (Figure 1A and 1B).

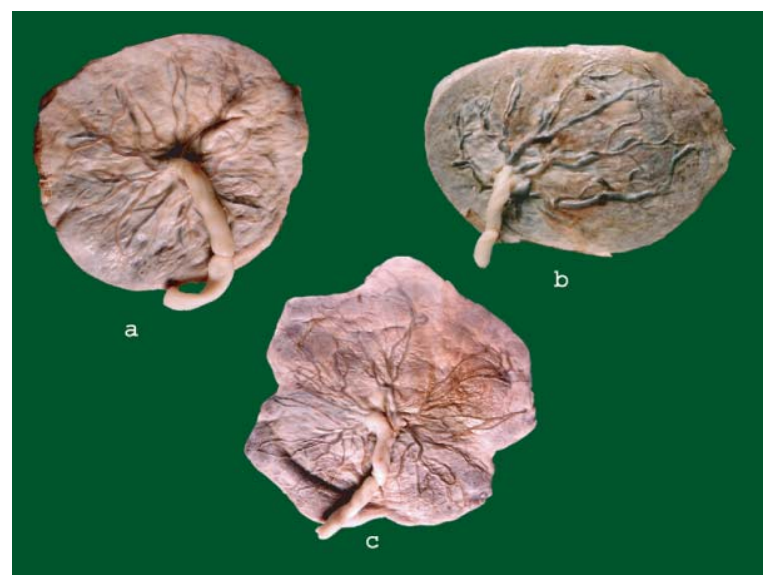

Fig.-1A: Different shapes of placenta, a. Circular, b. Oval, c. Irregular

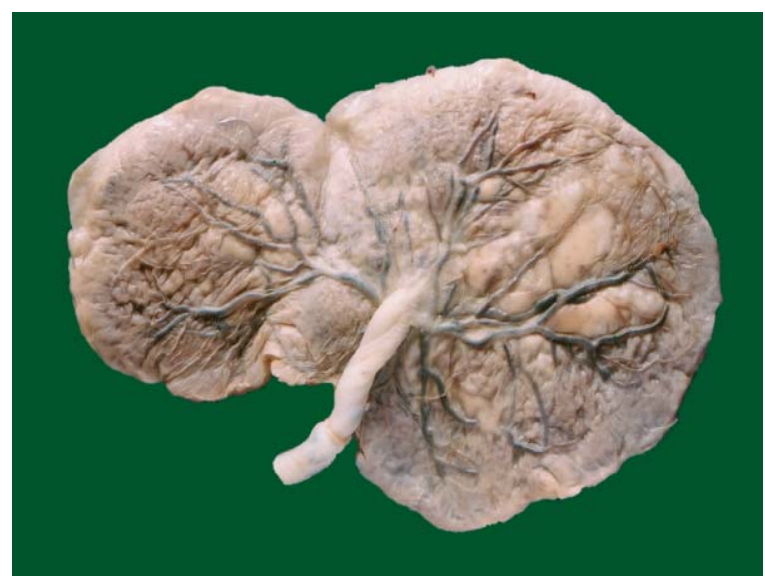

Fig.-1B: Placenta with an accessory lobe

\section{Diameter:}

The placenta was placed in a flat tray after trimming and mopping. At first, the maximum diameter was measured with a metallic scale graduated in centimeters $(\mathrm{cm})$. Then a second maximum diameter was taken at right angles to the first one. The mean of two measurements was considered as the diameter of the placenta expressed in centimeter $^{8}$ (Figure-2). 


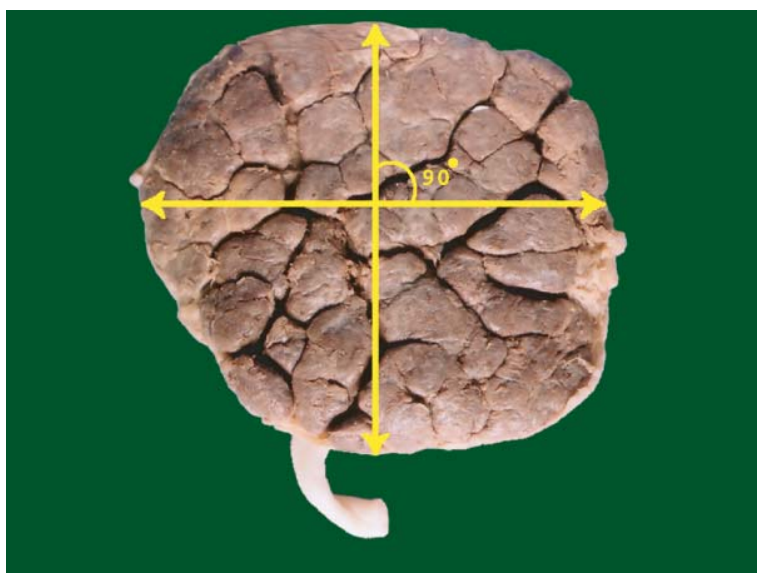

Fig.-2: Procedure of measurement of diameter of placenta

\section{Thickness:}

With a long needle placental thickness was measured at five points of each placenta. Each placenta was placed on fetal surface. The placenta was divided arbitrarily into three zones of equal parts by drawing two circles on the maternal surface. These circles cut the radius of the placenta into three equal parts. One thickness was measured from the centre of the central zone, two from middle and two from peripheral zone. The peripheral points were taken within the outer zone on a line perpendicular to the previous imaginary line. Finally the mean of all five measurements was calculated and considered as thickness of the placenta ${ }^{9}$ (Figure 3).

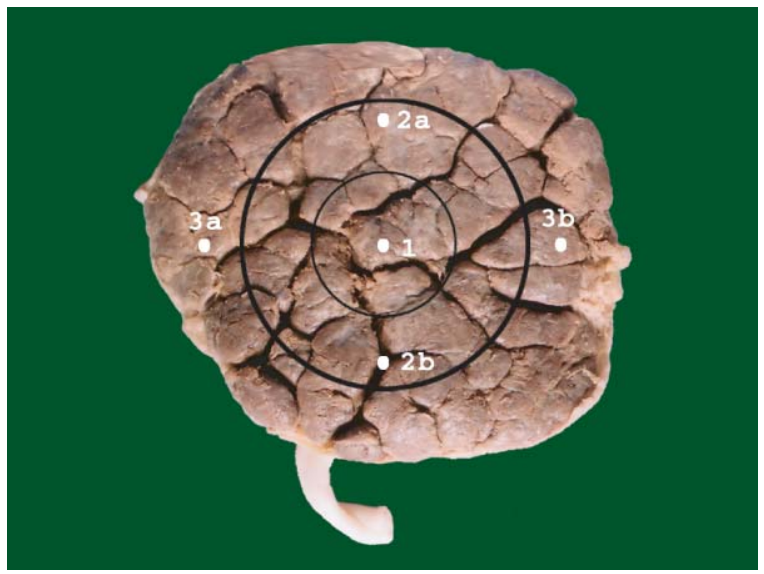

Fig.-3: Method of selecting sites from different zones of placenta for measurement of placental thickness. 1 represents the site in the arbitrary central zone; $2 a$ and $2 b$ the sites in the middle zone; $3 a$ and $3 b$ represent the peripheral zone.
4. Volume:

The volume of the placenta was measured by the water displacement method. The placenta was immersed in a water filled bucket which had an attached draining tube. The displaced water was collected in a pot and measured in a graduated cylinder marked in milliliters ( $\mathrm{ml})$.

\section{Number of Cotyledons:}

Each formalin-fixed placenta was taken on both hands. Then gentle pressure was applied on the central part of the fetal surface with thumbs of both hands while holding the periphery of the placenta with the other fingers. As a result, the cotyledons on the maternal aspect become prominent after separation between them. Then the placenta was put on a flat tray with maternal side facing upward by placing a block of paraffin on the fetal side. Then counting was started from the left side of the one end of the placenta going rightward and again turning back to the left in a manner of loop. This counting procedure was repeated until the other end of the placenta was reached. The total number of cotyledons was recorded ${ }^{10}$ (Figure 4).

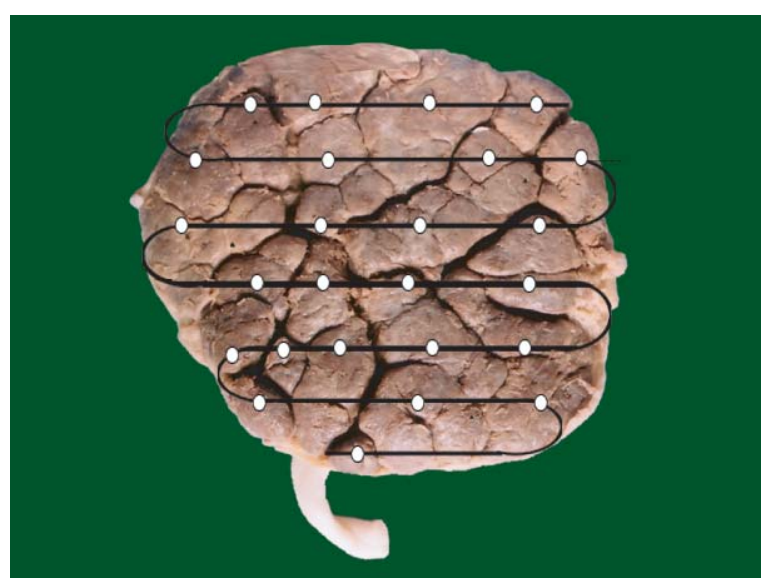

Fig.- 4: Procedure of counting of cotyledons.

\section{Result:}

1. Shape of the placenta:

In the present study, in group $A$ and group $B$, the number of oval shaped placenta was 10 (33.3\%) and 12 (40\%), the number of circular shaped placenta was $13(43.3 \%)$ and $10(33.3 \%)$, the number of irregular shaped placenta was 7 (23.3\%) and $8(26.7 \%)$ respectively (Table-I, and Figure $1 \mathrm{a}$, $1 \mathrm{~b}$ and 5). 
Table-I

Shape of placenta in the two study groups

\begin{tabular}{|c|c|c|c|c|c|}
\hline \multirow[t]{2}{*}{$\begin{array}{l}\text { Shape of } \\
\text { placenta }\end{array}$} & \multicolumn{2}{|c|}{$\begin{array}{c}\text { Group A } \\
(n=30)\end{array}$} & \multicolumn{2}{|c|}{$\begin{array}{c}\text { Group B } \\
(n=30)\end{array}$} & \multirow[t]{2}{*}{$P$ value } \\
\hline & No. & (\%) & No. & (\%) & \\
\hline Oval & 10 & (33.3) & 12 & $(40.0)$ & \\
\hline Circular & 13 & (43.3) & 10 & (33.3) & $>0.50^{\mathrm{ns}}$ \\
\hline Irregular & 7 & (23.3) & 8 & (26.7) & \\
\hline
\end{tabular}

Group A : Control

Group B : Preeclampsia

Statistical analysis done by Chi square test, ns = not significant

Table-II

Comparison of placental diameter, thickness, absolute volume and number of cotyledon between the two groups

\begin{tabular}{lccc}
\hline $\begin{array}{l}\text { Placental } \\
\text { parameters }\end{array}$ & $\begin{array}{c}\text { Group A } \\
(\mathrm{n}=30) \\
\text { Mean } \pm \text { SD }\end{array}$ & $\begin{array}{c}\text { Group B } \\
(\mathrm{n}=30) \\
\text { Mean } \pm \text { SD }\end{array}$ & P value \\
\hline Diameter (in cm) & $18.80 \pm 2.32$ & $16.08 \pm 2.08$ & $<0.001^{* \star *}$ \\
& $(15.2525 .00)$ & $(12.5021 .50)$ & \\
Thickness (in cm) & $1.59 \pm 0.39$ & $1.51 \pm 0.37$ & $>0.10^{\mathrm{ns}}$ \\
& $(1.002 .25)$ & $(1.002 .25)$ & $<0.001^{* * *}$ \\
Absolute & $389.83 \pm 81.45$ & $292.80 \pm 71.81$ & \\
Volume (in ml) & $(235.0610 .0)$ & $(175.0465 .0)$ & $<0.05^{*}$ \\
Number of & $15.77 \pm 2.80$ & $14.30 \pm 2.47$ & \\
Cotyledon & $(11.022 .0)$ & $(10.020 .0)$ & \\
\hline
\end{tabular}

Group A : Control

Group B : Preeclampsia

Figures in parentheses indicate range. Statistical analysis done by unpaired Student's 't' test, ns = not significant, ${ }^{\star / * * *}=$ significant

2. Diameter:

In the present study the mean $( \pm \mathrm{SD})$ diameter of the placenta was $18.80 \pm 2.32 \mathrm{~cm}$ in group $A$ and $16.08 \pm 2.08 \mathrm{~cm}$ in group B. So, it was evident that the diameter of the placenta was statistically different from each other at $\mathrm{P}<0.001$ (Table-II and Figure 6).
3. Thickness:

The mean $( \pm \mathrm{SD})$ thickness of the placenta was $1.59 \pm 0.39 \mathrm{~cm}$ in group A and $1.51 \pm 0.37 \mathrm{~cm}$ in group B. Statistically the difference between groups $A$ and $B$ was not significant (Table-II and Figure 6).

4. Volume:

The mean $( \pm S D)$ volume of the placenta in group $A$ and group $B$ was $389.83 \pm 81.45$ and $292.80 \pm 71.81$ 


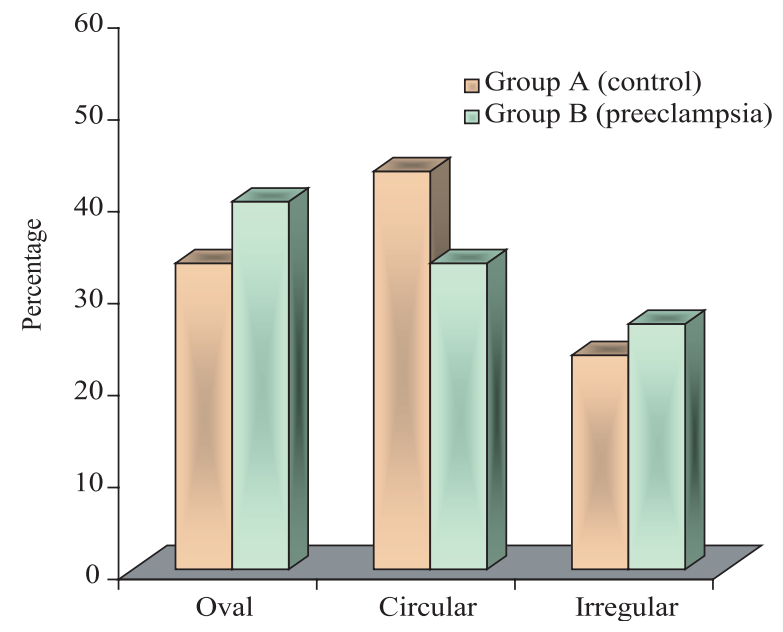

Fig.- 5: Shape of the placenta in two study groups

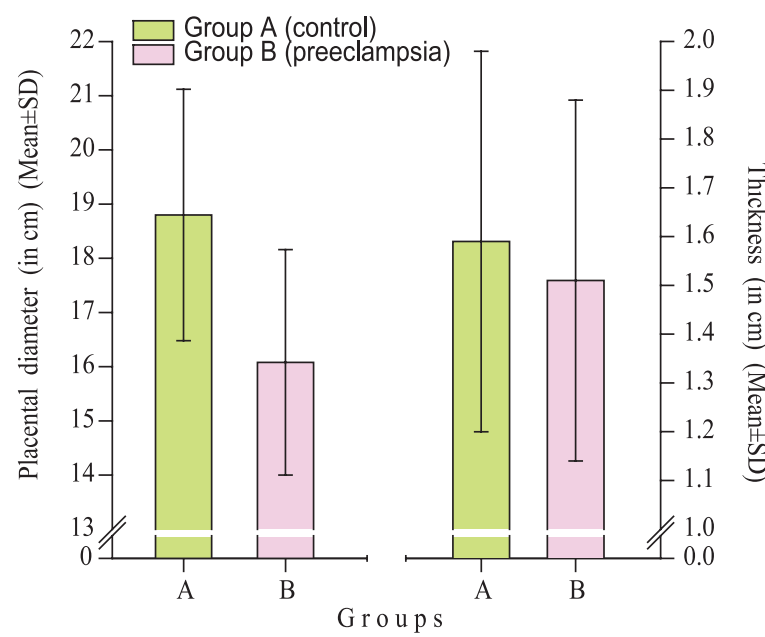

Fig.- 6: Placental diameter and thickness in two study groups

$\mathrm{ml}$ respectively. Statistically, the mean difference between group $A$ and group $B$ was significant at $\mathrm{P}<0.001$ (Table-Il and Figure 7).

5. Number of cotyledons:

In the present study, the mean ( \pm SD) number of cotyledon in group A and B was $15.77 \pm 2.80$ and $14.30 \pm 2.47$ respectively. Statistical analysis between groups $A$ and $B$ was significant at $P<0.05$ (Table-Il and Figure 8).

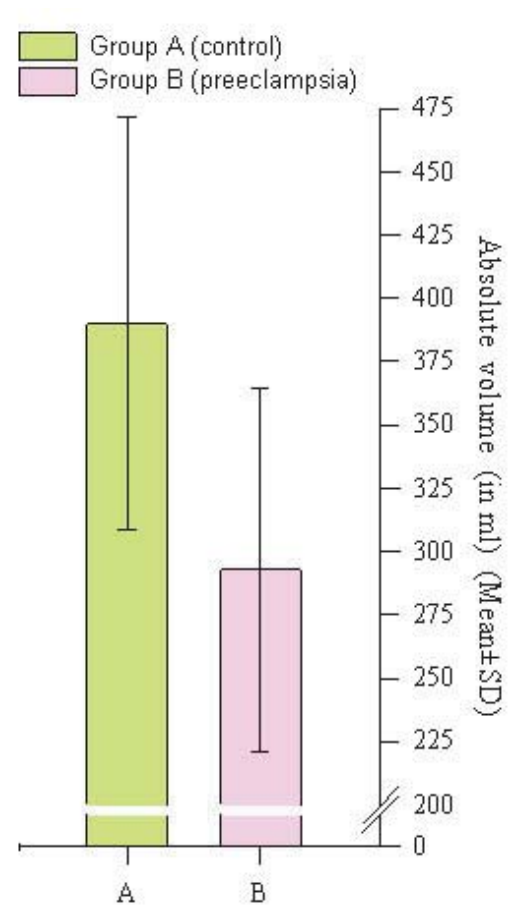

Fig.- 7: Placental volume in two study groups

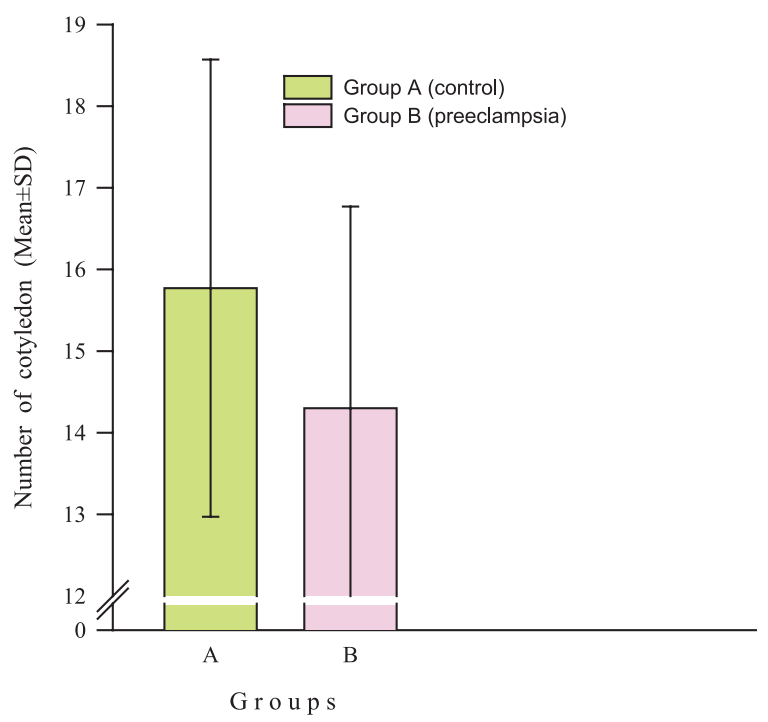

Fig.- 8: Number of Cotyledons in two study groups

\section{Discussion:}

Shape of the placenta:

In the present study, shape of the most placentae were oval (40\%) in preeclampsia group and most being circular (43.3\%) in control group. Shah ${ }^{11}$ found no clinical significance in oval or round shaped 
placentae. Irregular shaped placentae were seen in prematurity due to toxaemia.

Diameter, thickness and number of cotyledon:

In this study, diameter of placenta in preeclampsia group was significantly reduced. Teasdale ${ }^{12}$ found significant reduction of transverse diameter in preeclampsia group; this reduction seems to be due to the small size of placenta in preeclampsia group. Cibils $^{13}$ reported that the placentae from hypertensive patients were significantly smaller than the normal suggesting that the pathologic process interferes with the normal placental growth.

The mean number of cotyledon was reduced significantly $(p<0.05)$ in preeclampsia group.

Volume:

Absolute volume of placenta was significantly reduced in preeclampsia group. This is similar to the observation of Boyd and Scott ${ }^{14}$ and Teasdale ${ }^{12}$. Similar findings were also described by Aherne and Dunnill ${ }^{15}$ where volume of hypertensive placenta was significantly lower than the normal value at term.

This can be concluded that all values related to diameter, thickness, number of cotyledon and volume of placentae in preeclampsia group were found lower than that of control group and this was contributed to the insufficient blood supply due to preeclampsia.

\section{References:}

1. Bangladesh Demograhic and Health Survey Report 2007

2. Roberts JM, Cooper DW. Preeclampsia trio. Pathogenesis and genetics of preeclampsia. The Lancet 2001; 357: 53-6.

3. Soma H, Yoshida K, Mukaida T, Tabuchi Y. Morphological changes in the hypertensive placenta. Contrib Gynecol Obstet 1982; 9: 5875.

4. Robertson WB, Brosens I and Dixon HG. The pathological response of the vessels of the placental bed to hypertensive pregnancy. J Pathol Bacteriol 1967; 93: 581-92.
5. Norwitch ER, Chaur-Dong HSU, Rapke JT. Acute complication of preeclampsia. Clinical Obstet Gynecol 2002; 45 (2): 308-29.

6. Sibai BM. Diagnosis and management of gestational hypertension and preeclampsia. Obstet Gynecol 2003; 102: 181-92.

7. Godfrey KM, Redman CWG, Barker DJP and Osmond C. The effect of maternal anaemia and iron deficiency on the ratio of fetal weight to placental weight. Br J Obstet and Gynecol 1991; 98: 886.

8. Shanklin DR. The human placenta; a clinico pathologic study. Obstet Gynecol 1958 Feb; 11(2): 129-38.

9. Anwar S. Histomorphological changes of human placenta in Diabetes mellitus [thesis]. Dhaka: Dhaka Univ; 1999.

10. Laskar SP. Study of the umbilical cord in normal delivery and its relationship with maternal, fetal and placental factors [thesis]. Dhaka: Dhaka Univ; 1999.

11. Shah RK, Jagiwala KS, Vyas PK. Placental morphology and fetal growth in normal and abnormal pregnancies. Journal of Obstetrics and Gynecology of India 1985; 35: 1089-94.

12. Teasdale F. Histomorphometry of the human placenta in preeclampsia associated with severe intrauterine growth retardation. Placenta 1987; 8: 119-28.

13. Cibils LA. The placenta and newborn infant in hypertensive conditions.Am J Obstet Gynecol 1974 Jan; 118 (2): 256-70.

14. Boyd PA, Scott A. Quantitative structural studies on human placentas associated with preeclampsia, essential hypertension and intrauterine growth retardation. $\mathrm{Br} \mathrm{J}$ Obstet Gynecol 1985; 92: 714-21

15. Aherne W, Dunnill MS. Quantitative aspects of placental structure. J Pathol Bacteriol 1966; 91: 123-39. 